ISSN electrónico: 1585-5210

DOI: https://doi.org/10.14201/rmc2021174249252

\title{
LA LIBERTAD DE CONCIENCIA ANTE LA MUERTE
}

\section{Freedom of conscience in the face of death}

\author{
Antonio BLANCO MERCADÉ \\ Complejo Asistencial Universitario de León. \\ Correo electrónico: ablancomer@saludcastillayleon.es \\ Recibido: 11 de julio de 2021 \\ Aceptado: 14 de julio de 2021
}

"La meditación anticipada de la muerte es meditación anticipada de la libertad»

(Montaigne)

"Muerte no te enorgullezcas, aunque algunos te llamen poderosa y terrible, puesto que nada de eso eres. (...) Tras un breve sueño despertamos a la eternidad y la muerte dejará de existir, muerte morirás». Este soneto de John Donne (1.610) lo recita Emma Thompson interpretando el papel de una profesora de literatura que se enfrenta a la muerte en Amar la vida / Wit (2.001) de Mike Nichols. Cabría pensar que la esperanza de encontrar otra vida, eterna y mejor que esta, es un motivo suficiente para sonreír ante la muerte. Más aún, Teresa de Jesús ansiaba abandonar cuanto antes este valle de lágrimas, esta vida de tránsito que, para ella, era como pasar una mala noche en una mala posada; por eso escribió: "vivo sin vivir en mí y tan alta vida espero que muero porque no muero». El deseo de morir, aunque muy infrecuente, no es algo nuevo, porque la muerte es un hecho cultural, además de ser una realidad biológica universal e irremediable.

La vida (al menos esta vida, la que todos conocemos) no es el bien supremo, como a veces se nos quiere hacer creer. La prueba de ello es que, en situaciones extremas, muchas personas anteponen otros valores a su propia vida, lo que siempre supone una verdadera tragedia, pues con ella se pierde un valor importantísimo. Un buen ejemplo es el rechazo que los Testigos de Jehová tienen, por motivos religiosos, a recibir sangre, aunque ello les pueda conducir a la muerte. A algunos médicos esto les da 


\section{LA LIBERTAD DE CONCIENCIA ANTE LA MUERTE ANTONIO BLANCO MERCADÉ}

cierta aprensión y la situación generada puede dar lugar a conflictos en la práctica clínica; sin embargo, en principio, las decisiones de rechazar autónomamente cualquier tratamiento tienen que ser aceptadas y cumplidas ${ }^{1}$. En la actualidad sorprende que alguien anteponga la fe a su propia vida, pero, si bien las creencias religiosas no son racionales, tienen que ser respetadas. Lo que no se debe hacer es tratar de imponer a los demás los dogmas propios, desde posiciones fundamentalistas y siendo intolerantes con aquellos que piensan de modo distinto. En este sentido, nadie entendería, por ejemplo, que se prohibiesen las transfusiones de sangre por el hecho de que hay quienes creen que atentan contra un precepto divino.

Nuestra sociedad ya no obedece a un solo código ético, sino que aprueba la existencia de múltiples proyectos personales de vida buena. El derecho a la libertad ideológica y de conciencia permite a cada uno vivir de acuerdo con sus convicciones y creencias. En eso se fundamenta la autogestión de la vida, incluyendo el modo de su terminación, cuando ya se ha cumplido el proyecto vital o cuando no es posible llevarlo a cabo, debido, por ejemplo, a una enfermedad grave e incurable ${ }^{2}$. Así, un enfermo puede decir a su médico: «Doctor, le ruego que aparte de mí este sufrimiento insoportable, adelantándome la muerte» y el médico puede atender o no a esa petición, actuando también de acuerdo con su propia conciencia. Pero la muerte pertenece al moribundo y por eso se debe respetar la autonomía de su voluntad. Si el contenido de una creencia se impone a alguien que no la comparte, la decisión que este tome no será autónoma, sino heterónoma y carente de autenticidad moral. Solo cuando, en aras de la soberanía y la libertad propias, se delega en otro la voluntad, aunque pueda parecer paradójico se está tomando una decisión autónoma, como lo hiciera el mismo Dios hecho hombre: "Padre, si quieres, aparta de mí esta copa; pero no se haga mi voluntad, sino la tuya» ${ }^{3}$.

Hay que decir que quitar la vida no es intrínsecamente malo, que no es algo malo en sí mismo, siempre. La prohibición legal de quitar la vida a otro, el mandamiento que dice «no matarás» y el principio ético de no maleficencia, no son imperativos categóricos, sino deberes prima facie, que en ocasiones no se corresponden con el deber real de hacer o no hacer un acto determinado en circunstancias determinadas 4 . Son deberes que tienen excepciones y una de ellas puede ser la eutanasia, que consiste en una forma de ayudar a un ser humano a morir, prestándole ayuda para morir, en una situación extrema y en circunstancias determinadas.

Eutanasia es la actuación de un médico que produce la muerte de una persona de forma directa e intencionada mediante una relación causa-efecto única e inmediata, a petición informada, expresa y reiterada en el tiempo por dicha persona, y que se lleva a cabo en un contexto de sufrimiento debido a una enfermedad o padecimiento incurable que la persona experimenta como inaceptable y que no ha podido ser mitigado por otros medios ${ }^{5}$. Esto y solo esto es la eutanasia.

No se puede sembrar confusión atribuyendo a la eutanasia significados que le son ajenos, igual que hicieron los nazis cuando emplearon esa palabra para encubrir los asesinatos del programa Aktion T4, que consistía en eliminar a las personas que no cumplían los cánones de la raza aria; eso no era un plan de eutanasia, sino un aberrante genocidio. Sin duda es una improbidad equiparar la eutanasia a otras acciones que son absolutamente reprobables, entre otras cosas, porque la capacidad de entendimiento, la libertad y la voluntad de quien pide de forma expresa y reiterada la ayuda para morir, son condición sine qua non para llevarla a cabo. 


\section{LA LIBERTAD DE CONCIENCIA ANTE LA MUERTE ANTONIO BLANCO MERCADÉ}

Mar adentro (2.004) de Alejandro Amenabar, todavía desata pasiones e implica afectivamente al espectador. Javier Bardem interpreta a Ramón Sampedro, tetrapléjico que, seis años antes, había muerto clandestinamente con ayuda. Es un caso paradigmático de la eutanasia, que sigue siendo tema de debate, cuando no de enfrentamiento, en la sociedad ${ }^{6}$. Ramón prefería morir a seguir viviendo en unas condiciones que le producían un sufrimiento insoportable, pues sentía que llevaba treinta años viviendo dentro de un cadáver ${ }^{7}$. Se dice, con razón, que muchas personas en una situación parecida quieren vivir $y$, en efecto, existe el deber de dar apoyo a quienes, a pesar de sus malas condiciones de vida, demuestran en el día a día su capacidad de ser felices. Toda vida humana es valiosa, igualmente valiosa $y$, aunque la vida biológica tenga poca esperanza o sea de mala calidad, debe estar protegida ${ }^{8}$. Pero también hay que respetar la decisión firme de esa otra minoría de personas que, aun teniendo alternativas, prefieren adelantar su final y para ello nos piden ayuda desde la libertad de conciencia, el mismo principio que ampara a los profesionales que objetan a la eutanasia.

Para el psicólogo clínico Ramón Bayés, hay que individualizar el problema de los que solicitan la eutanasia y analizar cada caso con todas las implicaciones éticas que ello supone. Admitamos que la eutanasia puede ser una excepción válida en cuanto al modo y al momento de morir y ojalá cada uno de nosotros sepamos reconocer que "es posible que en algunas circunstancias muy especiales que en este momento no sabría precisar, yo mismo, que en el fondo de mi corazón soy contrario a la eutanasia, me sintiera impelido a pedirla, a recomendarla o incluso a practicarla» ${ }^{9}$.

Desde el reconocimiento de la libertad de conciencia en la diversidad, resulta difícil negar la legitimidad de actos excepcionales que adelantan el final de la vida y causan directamente la muerte por motivos humanitarios, cuando el sufrimiento físico, psicológico o espiritual es insoportable para el enfermo ${ }^{8}$.

\section{Referencias}

1. Comisión de Bioética de Castilla y León. Rechazo al tratamiento. Cuestiones éticas, deontológicas y jurídicas. Junta de Castilla y León, Consejería de Sanidad; 2013.

2. Gracia Guillén, D M. Morir a tiempo. La eutanasia y sus alternativas. Claves de la razón práctica. 2005; (152) 10-18.

3. Lucas, 22:42.

4. Ross, WD. Lo correcto y lo bueno. Salamanca: Sígueme; 1994.

5. Ley Orgánica 3/2.021, de 24 de marzo, de regulación de la eutanasia. BOE de 24 de marzo de 2021 (72):34037-34049.

6. García Sánchez, JE, García Sánchez, E. Mar adentro (2004) y Million Dollar Baby (2004). Dos Oscar a la medicina. Rev. Med. Cine. 2005; 1(2);25-26.

7. Sampedro, R. Cartas desde el infierno. Barcelona: Planeta; 2005.

8. Gracia Guillén, D M. Salir de la vida. En: Como arqueros al blanco. Madrid: Triacastela; 2004.

9. Bayés, R. Afrontando la vida, esperando la muerte. Madrid: Alianza; 2006. 


\section{LA LIBERTAD DE CONCIENCIA ANTE LA MUERTE ANTONIO BLANCO MERCADÉ}

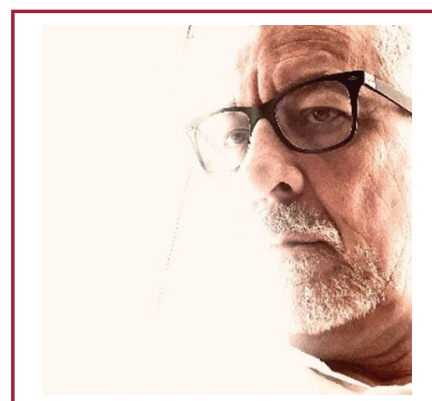

Antonio Blanco Mercadé es doctor en Medicina por la Universidad de Navarra y magíster en Bioética por la Universidad Complutense de Madrid. Presidente del Comité de Ética Asistencial del Área de Salud de León, presidente de la Comisión de Bioética de Castilla y León (2012-2020), vicepresidente de la Asociación de Bioética Fundamental y Clínica (2011-2015), vocal de la Comisión Central de Deontología del Consejo General de Colegios de Médicos (2017-2021), presidente de las Comisiones de Ética y Deontología del Consejo de Colegios de Médicos de Castilla y León (2010-2019) y del Colegio de Médicos de León (2007-2019). 